\title{
A critical control section for flume flows
}

\section{Section critique de contrôle d'un écoulement en canal}

\author{
PAR E. KOVACัCI $\stackrel{\vee}{\mathrm{C}}$ \\ FAGULTY OF GIVIL ENGINEERING, LJUBLJANA
}

\begin{abstract}
Assuming given relationships between water level and discharge or total energy line and discharge for a free-surface, sub-critical flow, it is proposed to determine a cross-section through which the flow rates and total energy lines are the same but the flow is critical, thus forming a control section. The case of a fume whose discharge relationship is determined by its slope and roughness is taken as an example, it being proposed to determine the restricted cross-section required downstream in order to maintain the same relationship between total energy line and discharge, but for critical flow.
\end{abstract}

It seems appropriate to call the reader's attention to the fact that in the present article we are not concerned with a new method for the determination of the critical depth in open channels, as the title of the article might suggest. There are known already several ways which lead to the determination of critical depths in cross-sections of various shapes. In addition to the common conception of the critical depth in a cross-section, however, we are introducing the conception of the critical section. As understood by the author, the critical section is a specially shaped cross-section of least area, which, if placed as a local constriction in a channel, would not provoke any water level changes upstream from the constriction. Therefore, the specific energy heights for the channel flow, remaining unchanged too, would be at the same time critical energy heights for the flow in the local constriction, where, supposedly, a critical flow regime occurs. Apparently, the shape and the area of the critical section depend entirely on the geometry of the channel and the hydraulic conditions governing the flow in the channel.

In the foregoing definition of the critical section obviously a nonrealistic presumption is implied, i.e., a channel constriction without energy loss due to acceleration and deceleration of the flow. Needless to say, that energy losses of that kind should be taken into account as

\begin{abstract}
Ine relation niveau-debit ou plan de chargedébit étant donnée pour un écoulement $\grave{a}$ surface libre en régime flubial, on se propose d'établir une section dans laquelle les mêmes débits s'éconlent avec les mêmes plans de charge, mais en régime critique, ce qui constitue une section de controle. Par exemple, un canal a une loi de débit déterminée par la pente et la rugosité; on se propose de déterminer quelle est la section rétrécie qu'il fant placer en aval pour avoir la même loi de débit (relation plan de charge-débit), l'écoulement étant en régime critique.
\end{abstract}

Il paraît opportun d'attirer l'attention du lecteur sur le fait que, dans le présent article, il ne s'agit pas d'une nouvelle méthode pour la détermination de la profondeur critique dans les canaux ouverts, ainsi que le titre semblerait le suggérer. Il existe déjà plusieurs procédés connus, conduisant à la détermination des profondeurs critiques dans les sections transversales de différentes formes. Outre la notion classique de la profondeur critique, dans une section transversale, la présente étude introduit celle d'une section critique. Suivant la pensée de l'auteur, cette section correspond à une section transversale, d'une forme particulière, et d'une aire minimale, laquelle, étant disposée dans un canal de manière à constituer un étranglement localisé dans celui-ci, ne provoquerait aucune variation du plan d'eau situé à l'amont dudit étranglement. Dans ces conditions, puisque les charges spécifiques, correspondant au débit dans le canal, ne varieraient pas non plus, elles représenteraient également les charges critiques, pour l'écoulement par l'étranglement où on suppose l'existence d'un régime d'écoulement crilique. Apparemment la forme et l'aire de la section critique sont entic̀rement fonction à la fois, de la géométrie du canal, et du régime hydraulique déterminant l'écoulement à l'intérieur de celui-ci.

Il est bien évident que la définition précédente, de la section critique, se base sur une hypothise, ne correspondant guère à la réalité, suivant 
corrections of the specific energy heads and added to the energy heights upstream from the constriction. Investigations concerning similar energy 'losses have been published recently by G. Formica. [1].

From the two possible flow regimes in an open channel only the subcritical flow regime will be taken into consideration in the present article.

The preceding definition of the critical section might be illustrated by the following example:

For a rate of flow $\mathrm{Q}=0,279 \mathrm{~m}^{3} / \mathrm{sec}$ in a circular cross-section of diameter $\mathrm{D}=1,0 \mathrm{~m}$ the critical depth $\eta_{c}=0,295 \mathrm{~m}$, the pertinent area $\sigma_{c}=0,194 \mathrm{~m}^{2}$, the minimum specific energy height $\mathbf{E}_{c}=0,407 \mathrm{~m}$, if the Coriolis' factor $\alpha=1,05$. It follows from our computations, however, that the same discharge as above, flowing with an energy height $\mathrm{E}=0,527 \mathrm{~m}$, depending on the hydraulic parameters of the channel, would require a critical section area

$$
\mathrm{S}_{c}=0,164^{2}
$$

with the pertinent depth :

$$
y_{\varepsilon}=0,373 \mathrm{~m} \text {. }
$$

Moreover, the shape of the critical section would permit a critical regime flow through the constriction also for any other discharge without change of its specific energy head (Fig. 1). laquelle l'étranglement dans le canal ne serait le siègle d'aucune perte d'énergie due à l'accélération et au ralentissement de l'écoulement. Il est nécessaire, bien entendu, de tenir compte de ces pertes d'énergie, au moyen de corrections appliquées aux charges spécifiques, et s'ajoutant à la charge totale à l'amont de l'étranglement. Des études sur des pertes d'énergie analogues ont été publiées dernièrement par G. Formica [1].

Des deux régimes d'écoulement possibles dans un canal ouvert, nous ne considérerons, dans le présent article, que le régime hypo-critique ou fluvial.

Nous pouvons préciser la définition précédente de la section critique au moyen de l'exemple suivant :

Soient le débit $Q=0,279 \mathrm{~m}^{3} / \mathrm{s}$, dans une section circulaire de diamètre $\mathrm{D}=1,0 \mathrm{~m}$, la profondeur critique $\eta_{c}=0,295 \mathrm{~m}$, l'aire de section correspondante $\sigma_{c}=0,194 \mathrm{~m}^{2}$, la charge spécifique minimale $\mathrm{E}_{6}=0,407 \mathrm{~m}$, le coefficient de Coriolis $\propto$ étant 1,05. D'après nos calculs, cependant, ce même débit, s'écoulant avec une hauteur d'énergie $\mathrm{E}=0,527 \mathrm{~m}$, conditionné par les paramètres hydrauliques du canal, nécessiterait une aire de section critique

$$
\mathrm{S}_{\mathrm{o}}=0,164 \mathrm{~m}^{2} \text {, }
$$

et une profondeur correspondante, $y_{c}=0,373 \mathrm{~m}$. En outre, la forme de la section critique permettrait également un écoulement, en régime critique, par l'étranglement, pour n'importe quel charge spécifique correspondante (fig. 1).
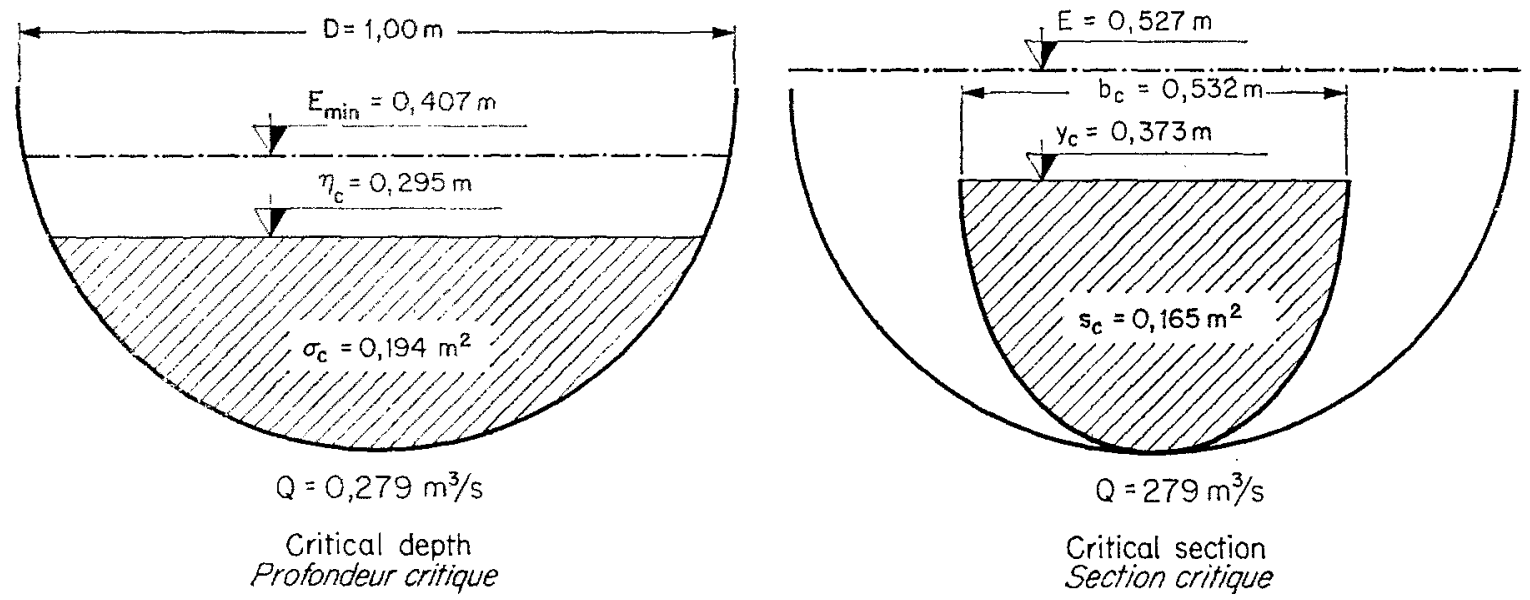

FiG. 1

Investigations carried out till now show that the critical section can be found by way of :

a) an analytical solution, and

b) a graphical construction.
Les études effectuées jusqu'à ce jour ont montré qu'il est possible de déterminer la section critique au moyen :

- d'une solution analytique,

- d'une construction graphique. 


\section{The analytical solution}

If the area $\sigma$ and the wetted perimeter $\mathrm{P}$ of a channel cross-section can be expressed as functions of the depth $\eta, \sigma=f(\eta)$ and $P=\mathrm{F}(\eta)$, then with the parameters $i$ (= slope) and $n$ (= Manning's velocity factor) taken as constants over the depth also a function $S_{c}=f\left(y_{e}\right)$, defining the critical section, ought to be determinable. $\mathrm{S}_{c}$ stands for the area of the critical section.

Let us specify the function $f(\eta)$ in the form

$$
\xi=\frac{1}{\sigma^{2}}=f(\eta)
$$

where

$\xi=$ the abscissa,

$\sigma=$ the area of the channel cross-section,

$\eta=$ the ordinate.

This curve, proposed by F. F. Escoffier [2], if crossed by a straight line, $\eta=\mathrm{E}-5 \operatorname{tg} \beta$, through the points $(\xi=0, \eta=E)$ under the slope (Fig. 2) :

$$
\operatorname{tg} \beta=\frac{d \eta}{d \xi}=\frac{\alpha \mathrm{Q}^{2}}{2 g}
$$

gives the intersections $T_{1}\left(\xi_{1} \eta_{1}\right)$ and $T_{2}\left(\xi_{2}, \eta_{2}\right)$, which determine respectively the subcritical and the supercritical flow with the specific encrgy height $E$. If a line tangent to the curve $\xi=1 / \sigma^{2}$ is drawn parallel to the line $\eta=E-\xi \operatorname{tg} \beta$, then the point of tangency $A$ determines the critical depth $\eta_{c}$ and the critical depth area $\sigma_{c}=1 / \sqrt{\xi}$, the intercept $E_{\min }$ on the ordinate axis being the minimum specific energy height for the discharge $Q$. This is verified, as follows:

$$
\begin{aligned}
\xi & =1 / \sigma^{2} \\
d \xi & =-\left(2 / \sigma^{3}\right) d \sigma \\
d \sigma & =b \cdot d \eta
\end{aligned}
$$

where $b$ stand's for the width at the water level. Hence:

$$
d \eta / d \xi=-\sigma^{3} / 2 b .
$$

Replacing $d r_{1} / d \xi$ by $\alpha Q^{2} / 2 g$ and omitting the minus sign we obtain:

$$
\frac{\sigma^{3}}{2 b}=\frac{\alpha Q^{2}}{2 g}
$$

which is the well known condition for the critical flow. For the same discharge $Q$ in sub-

\section{La solution analytique}

Lorsqu'il est possible d'exprimer l'aire $\sigma$ et le périmètre mouillé $P$, de la section d'un canal, par des fonctions de la profondeur $\eta$,

soil : $\quad \sigma=f(\eta)$, et $\mathrm{P}=\mathrm{F}(\eta)$,

il devrait également être possible, en principe, de déterminer, en admettant des valeurs constantes pour les paramètres $i$ (pente) et $n$ (coefficient de vitesse de Manning), une fonction $\mathrm{S}_{i}=f\left(y_{\mathrm{c}}\right)$, définissant la section critique; l'aire de celle-ci est définie par $\mathrm{S}_{c}$.

Définissons d'abord la fonction $f(\eta)$ sous la forme :

$$
\xi=\frac{1}{c^{2}}=f(\eta)
$$

avec (fig. 2) :

$\xi=$ l'abscisse,

$\sigma=$ l'aire de la section transversale du canal, $\eta=$ lordonnée.

Lorsque cette courbe (proposée pour la première fois par F.F. Escoffier [2]) est coupée par une droite $\eta=E-\xi \operatorname{tg} \beta$ passant les points

$$
(\xi=0, \eta=\mathrm{E})
$$

et dont la pente est donnée par :

$$
\operatorname{tg} \beta=\frac{d \eta}{d_{\xi}^{\xi}}=\frac{\alpha \mathrm{Q}^{2}}{2 g}
$$

elle définit les intersections $\mathrm{T}_{1}\left(\xi_{1} \eta_{1}\right)$ et $\mathrm{T}_{2}\left(\xi_{2} \eta_{2}\right)$, dont la première détermine l'écoulement fluvial, et la deuxième l'écoulement hyper-critique ou torrentiel, correspondant à la charge spécifique $E$. Le point de tangence $A$, d'une tangente à la courbe donnée par $\xi=1 / \sigma^{2}$, et tracée parallèle à la droite $\eta=\mathbf{E}-\xi \operatorname{tg} \beta$, détermine $\dot{a}$ la fois, la profondeur critique $\eta_{c}$, el l'aire de la profondeur critique $\sigma_{c}=1 / \sqrt{\xi}$; le point de recoupement $E_{\text {min }}$, sur l'ordonnće, correspond à la charge spécifique minimale pour le débit $Q$. Ceci se vérifie par :

$$
\begin{aligned}
\xi & =1 / \sigma^{2} \\
d \xi & =-\left(2 / \sigma^{3}\right) d \sigma \\
d \sigma & =b \cdot d r_{1}
\end{aligned}
$$

$b$ représentant la largeur au niveau du plan d'eau.

D'où

$$
d r_{1} / d \xi=-\sigma^{3} / 2 b .
$$

En remplaçant $d \eta / d \xi$ par $\alpha Q^{2} / 2 g$, et en omettant le signe négatif, nous obtenons :

$$
\frac{\sigma^{3}}{2 b}=\frac{a Q^{2}}{2 g}
$$


critical flow the specific energy height $\mathrm{E}>\mathrm{E}_{\mathrm{min}}$. Similarly as before, by the specific energy height $E$ a cross-section of the minimum area $S_{0}$ and the depth $y_{c}$ is specified, if the rate of flow $\mathrm{Q}$ is to be conveyed through this critical section. The values of $\mathrm{S}_{e}$ and $y_{c}$ are given by the coordinates of the point of tangency $B$ between the line:

$$
\eta=\mathrm{E}-\xi \frac{\alpha \mathrm{Q}^{2}}{2 g}
$$

and the yet unknown curve $x=f(y)$.

By flow conditions in the channel a family of straight lines:

$$
\eta=\mathrm{E}-\xi \frac{\alpha \mathrm{Q}^{2}}{2 g}
$$

is defined, which are tangent to a curve

$$
x=\left(1 / S^{2}\right)=f(y),
$$

i.e. the enveloppe of the family. The equation of the family can therefore be written in the form:

where:

$$
y=\mathrm{E}-x \cdot y^{\prime}
$$

$$
y^{\prime}=\alpha Q^{2} / 2 g(\text { Fig. 2) }
$$

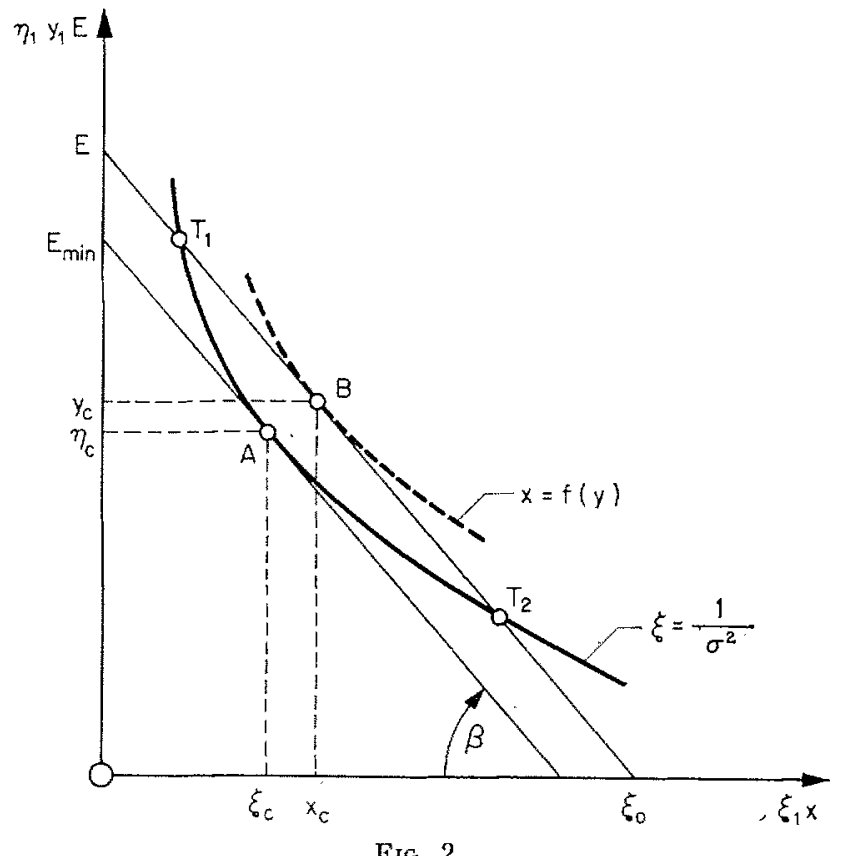

Putting:

$$
\mathrm{E}=\eta+\xi y^{\prime}
$$

we obtain the differential equation:

$$
y=\eta+\xi \cdot y^{\prime}-x y^{\prime}
$$

or in a more general form:

$$
y=f\left(y^{\prime}\right)+x \cdot y^{\prime}
$$

known as Clairaut's differential equation. The singular integral of this equation would yield immedialely the envelope $x=f(y)$. The sin- qui représente la condition classique pour l'écoulement criticue. La charge spécifique correspondant au même débit $Q$, en régime fluvial, est donnée par $\mathrm{E}>\mathrm{E}_{\text {min. }}$. Comme précédemment, la charge spécifique $\mathrm{E}$ définit la section dont l'aire minimale $\mathrm{S}_{c}$ et la profondeur $y_{c}$ sont nécessaires pour que le débit $Q$ puisse s'écouler par cette section critique. Les valeurs pour $S_{c}$ et pour $y_{c}$ sont données par les coordonnées du point de tangence $B$ de la ligne:

$$
\eta=\mathrm{E}-\xi \frac{\alpha \mathrm{Q}^{2}}{2 g}
$$

et de la courbe inconnue pour l'instant, correspondant à $x=f(y)$.

Le régime d'écoulement, dans le canal, définit une famille de droites :

$$
\eta=\mathrm{E}-\frac{\alpha \mathrm{Q}^{2}}{2 g}
$$

lesquelles sont tangentes à une courbe

$$
x=\left(1 / \mathrm{S}^{2}\right)=f(y),
$$

c'est-à-dire à l'enveloppe de cette famille. L'équation de la famille peut donc être écrite sous la forme :

$$
y=\mathrm{E}-x \cdot y^{\prime}
$$

avec :

$$
y^{\prime}=\alpha \mathrm{Q}^{2} / 2 g(\text { fig. } 2)
$$

Si nous écrivons :

$$
\mathrm{E}=n+\xi y^{\prime}
$$

nous obtenons l'équation différentielle :

$$
y=\eta+\xi \cdot y^{\prime}-x y^{\prime}
$$

soit, dans une forme plus générale :

$$
y=f\left(y^{\prime}\right)+x \cdot y^{\prime}
$$

Cette dernière équation est dite «équation différentielle de Clairaut», dont l'intégrale singulière fournirait directement l'enveloppe

$$
x=f(y) \text {. }
$$

Cependant, afin d'obtenir la solution singulière, il est d'abord nécessaire d'éliminer $y^{\prime}$ des équations :

$$
\begin{aligned}
& y=f\left(y^{\prime}\right)+x \cdot y^{\prime} \\
& x+f^{\prime}\left(y^{\prime}\right)=0
\end{aligned}
$$

Mais, comme les variables $\xi$, $\eta$, et $y^{\prime}$ interviennent dans des formules compliquées, et qu'ainsi 
gular solution requires, however, the elimination of $y^{\prime}$ from the equations:

$$
\begin{aligned}
& y=f\left(y^{\prime}\right)+x \cdot y^{\prime} \\
& x+f^{\prime}\left(y^{\prime}\right)=0
\end{aligned}
$$

In view of the fact that the variates $\xi, r_{i}, y^{\prime}$ are involved in complicated formulae and therefore $\xi$ and $\eta$ practically not expressible in terms of $y^{\prime}$, the singular solution does not appear attainable.

If we bring the equation $y=\eta+\xi \cdot y^{\prime}-x \cdot y^{\prime}$ to the one-parameter form, expressing $\xi$ and $y^{\prime}$ in terms of $\eta$, we have:

$$
y=\eta+\varphi(\eta) \cdot \psi(\eta)-x \cdot \psi(\eta)
$$

Derivating this equation with respect to the parameter $\eta$ and putting:

$$
d y / d \eta=0
$$

we obtain:

$$
1+\varphi^{\prime}(\eta) \cdot \psi(\eta)+\varphi(\eta) \psi^{\prime}(\eta)-x \psi^{\prime}(\eta)=0
$$

For various values of the parameter $\eta$ the corresponding values of $x$ can be computed from this equation. The values of the depths $y$ result from the equation $y=\mathrm{E}-x \cdot y^{\prime}$, and the water level widths $b$ are obtained by means of the expression:

$$
b=\frac{\mathrm{S}^{3} g}{\alpha \mathrm{Q}^{2}}
$$

Finally, by a set of values $y$ and $b$ the critical section can be plotted readily.

\section{Example:}

Let the channel have a circular cross-section of radius $r$, Manning's factor $n$, slope $i$, and Coriolis' factor $\alpha$. The depth $\eta$, the area $\sigma$, and the hydraulic radius $R$ can be expressed by the radius $r$ and the central angle 1 as the sole variate, as follows:

$$
\begin{aligned}
\eta & =r \cdot[1-\cos (\omega / 2)] \\
\sigma & =\left(r^{2} / 2\right)(\hat{\omega}-\sin \omega) \\
\mathrm{R} & =r \cdot(\hat{\omega}-\sin \omega) / 2 \hat{\omega}
\end{aligned}
$$

Putting:

$$
\xi=\varphi(\omega)=1 / \sigma^{2}=4 /\left[r^{4}(\hat{\omega}-\sin \omega)^{2}\right]
$$

and :

$$
y^{\prime}=\psi(\omega)=\alpha Q^{2} / 2 g
$$

and introducing:

$$
\mathrm{Q}=\frac{1}{n} i^{1 / 2} \mathrm{R}^{2 / 3} \frac{r^{2}}{2}(\hat{\omega} \cdots \sin \omega)
$$

il est pratiquement impossible d'exprimer $\xi$ et $\eta$ en fonction de $y^{\prime}$, il n'est sans doute pas possible d'obtenir cette solution singulière.

Si nous réduisons l'équation $y=\eta+\xi \cdot y^{\prime}-x \cdot y^{\prime}$ à la forme d'une équation à paramètre unique, en exprimant $\xi$ et $y^{\prime}$ en fonction de $\eta$, nous avons :

$$
y=\eta+\varphi(\eta) \cdot \psi(\eta)-x \cdot \psi(\eta)
$$

En tirant les dérivées de cette équation, par rapport au paramètre $\eta$, et en dérivant:

$$
d y / d n=0
$$

nous obtenons :

$$
1+\varphi^{\prime}(\eta) \cdot \psi(\eta)+\varphi(\eta) \psi^{\prime}(\eta)-x \psi^{\prime}(\eta)=0
$$

Cette dernière équation nous permet de calculer les valeurs de $x$ correspondant à différentes valeurs du paramètre $\eta$. Les valeurs des profondeurs $y$ sont obtenues à partir de l'équation $y=\mathrm{E}-x \cdot y^{\prime}$, et les largeurs, au niveau du plan d'eau $b$, se calculent à partir de la relation :

$$
b=\frac{\mathrm{S}^{3} g}{x \mathrm{Q}^{2}}
$$

Enfin, une série de valeurs, ainsi calculées, pour $y$ et pour $b$, permet de tracer sans aucune difficulté le profil de la section critique.

\section{EXEMPLE :}

Soit un canal de section circulaire dont le rayon est $r$, avec le coefficient de Manning $n$, la pente $i$, et le coefficient de Coriolis $\alpha$. La profondeur $\eta$, la section $\sigma$, et le rayon hydraulique $R$, peuvent être exprimés en fonction, uniquement, du rayon $r$, avec, pour seule variable, l'angle au centre $\omega$, par les relations :

$$
\begin{aligned}
\eta & =r \cdot[1 \cdot-\cos (\omega / 2)] \\
\sigma & =\left(r^{2} / 2\right)(\hat{\omega}--\sin \omega) \\
\mathrm{R} & =(r \cdot(\hat{\omega}-\sin \omega) / 2 \hat{\omega}
\end{aligned}
$$

En écrivant :

$$
\xi=\xi(\omega)=1 / \sigma^{2}=4 /\left[r^{4}(\hat{\omega}-\sin \omega)^{2}\right]
$$

et :

$$
y^{\prime}=\bigcup(\omega)=\alpha \mathrm{Q}^{2} / 2 g
$$

et, en inlroduisant :

$$
\mathrm{Q}=\frac{1}{n} i^{1 / 2} \mathrm{R}^{2 / 3} \frac{r^{2}}{2} \cdot(\omega-\sin \omega)
$$


we have finally:

$$
\psi(\omega)=K \frac{r^{16 / 3}}{\hat{\omega}^{4 / 3}}(\bar{\omega}-\sin \omega)^{10 / 3}
$$

where:

$$
\mathrm{K}=\frac{\alpha i}{n^{2} 2 g} \cdot \frac{1}{4} \cdot \frac{1}{2^{4 / 3}}
$$

The equation of the one-parameter family of straight lines is:

$$
y=r \cdot[1-\cos (\omega / 2)]+\varphi(\omega) \cdot \psi(\omega)-x \psi(\omega),
$$

The derivative with respect to $\omega$ is :

$$
\frac{d y}{d \omega}=\frac{1}{2} r \sin \frac{\omega}{2}+\varphi^{\prime}(\omega) \cdot \varphi(\omega)+\psi(\omega) \cdot \psi^{\prime}(\omega)-x \psi^{\prime}(\omega)=0
$$

Here:

$$
o^{\prime}(\omega)=-\frac{8}{r^{4}} \cdot \frac{1-\cos \omega}{(\omega-\sin \omega)^{3}}
$$

and:

$$
\mu^{\prime}(\omega)=\mathrm{K} \frac{r^{16 / 3} \cdot}{\hat{\omega}^{8 / 3}}\left[\frac{10}{3}(\omega--\sin \omega)^{7 / 3}(1-\cos \omega) \widehat{\omega}^{4 / 3}-\frac{4}{3} \hat{\omega}^{1 / 3}(\hat{\omega}-\sin \omega)^{10 / 3}\right]
$$

Nous obtenons, pour des valeurs choisies du paFor chosen values of the parameter $\omega$ we obtain the corresponding values of $x$ from:

$$
x=\frac{1 / 2 \cdot r \cdot \sin (\omega / 2)+\varphi^{\prime}(\omega) \cdot \psi(\omega)+\varphi(\omega) \cdot \psi^{\prime}(\omega)}{\psi^{\prime}(\omega)}
$$

Hence the area of the critical section

$$
\mathrm{S}=(1 / x)^{1 / 2} \text {. }
$$

The depth $y$ and the widtl $b$, however, are computed as indicated above.

\section{The graphical construction}

Witfi irregular cross-sections, where the functions $\sigma=f(\eta)$ and $\mathrm{P}=\mathrm{F}^{\prime}(\eta)$ can not be deter-

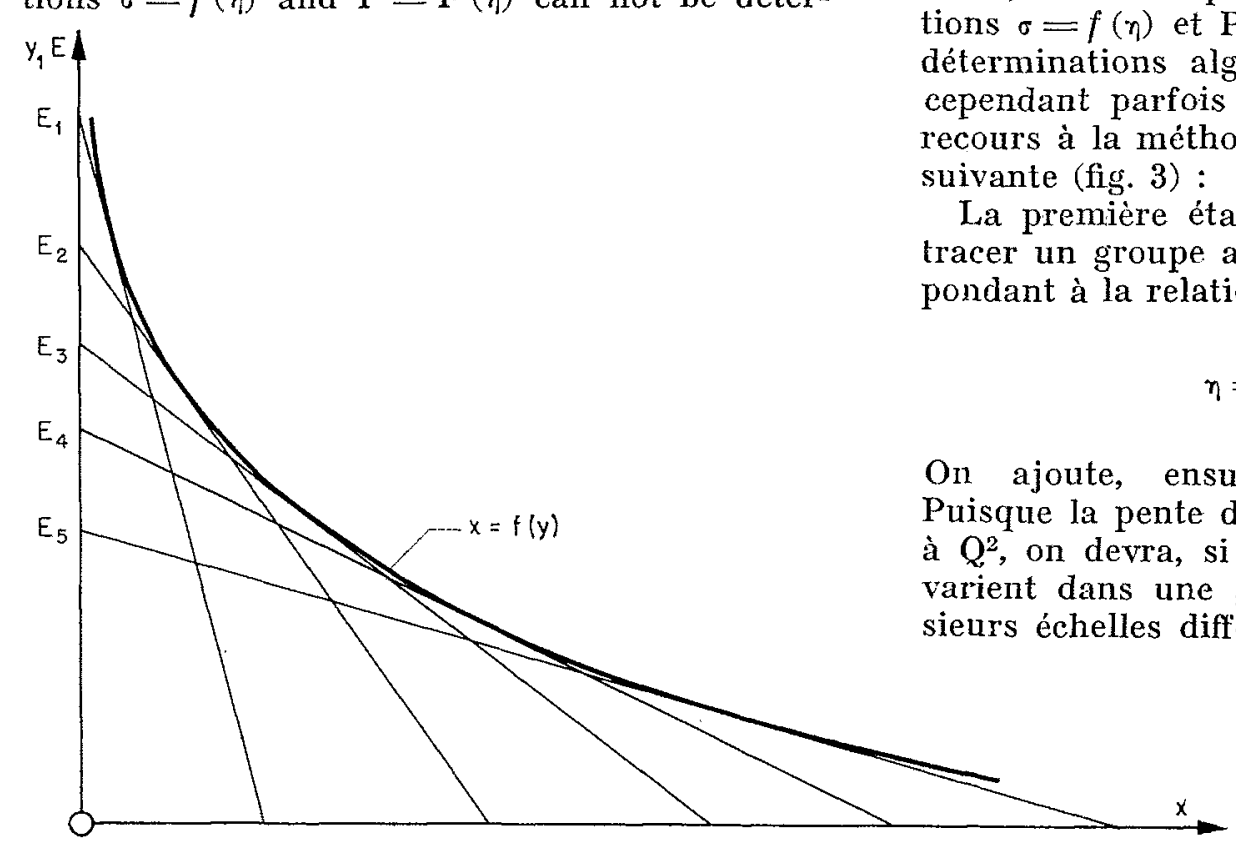

FIG. 3
Cette équation nous fournit également la valeur de la section critique $S=(1 / x)^{1 / 2}$. La profondeur $y$, et la largeur $b$, sont toutefois calculées de la manière exposée plus haut.

\section{La construction graphique}

Lorsque les sections considérées sont irrégulières, de sorte que la détermination des fonctions $\sigma=f(\eta)$ et $\mathrm{P}=\mathrm{F}(\eta)$ devient difficile (des déterminations algébriques approchées peuvent cependant parfois suffire), nous pouvons avoir recours à la méthode de construction graphique uivante (fig. 3) :

La première étape de la méthode consiste à tracer un groupe assez dense de droites, correspondant à la relation :

$$
\eta=\mathrm{E}-\xi \frac{\alpha \mathrm{Q}^{2}}{2 g}
$$

On ajoute, ensuite, l'enveloppe $x=\left(1 / \mathrm{S}^{2}\right)$. Puisque la pente des droites est proportionnelle $Q^{2}$, on devra, si les valeurs considérées de $Q$ éns une ganme étendue, prévoir plusieurs échelles différentes pour l'abscisse. 
mined easily - approximate algebraic functions might be sufficient sometimes - the following graphical construction can be adopted (Fig. 3):

Firstly, a fairly dense set of straight lines:

$$
\eta=\mathrm{E}-\xi \frac{\alpha \mathrm{Q}^{2}}{2 g}
$$

is plotted and the envelope curve $x=\left(1 / S^{2}\right)$ drawn. As the slope of the lines is proportional to the square of $Q$, various scales for the abscissa axis will be necessary, if the values of $Q$ vary within a wide range.

Secondly, departing from the lowest practical value of $y$, the corresponding values of $S$ are computed with the values of $x$ read off the envelope curve for small increments of $y$.

Thirdly, for the lowest value of $\mathrm{S}$ a parabolic shape of the critical section is assumed, and the width $b$ calculated from

$$
b=\frac{3 \mathrm{~S}}{2 y}
$$

For the next depth $y$ the width $b_{1}$ is obtained by means of the expression

$$
\left(y_{1}-y\right) \cdot \frac{b_{1}+b}{2}=\mathrm{S}_{1}-\mathrm{S},
$$

and in the same way for the subsequent values of $y$. Finally a smooth curve is drawn through the plotted points, the curve representing the critical section.

\section{Applications}

Apart from its interesting hydraulic characteristics, the critical section could have useful applications in irrigation and drainage works. The constricted portion of a Venturi or critical depth flume for discharge measurements could be given the shape of the critical section of the channel, which would ensure the smallest water level changes in the channel. Further experimental research will be necessary to clear the question of the degree of accuracy that could be attained in predicting water levels upstream from a critical section.

In channel reaches, extending upstream from drops or chutes, water level depressions causing bed erosion could be prevented if the crosssection at the drop be shaped as a critical section. It was this latter application that initiated our investigations of the critical section.
La deuxième étape consiste à calculer en partant de la plus petite valeur pratique pour $y$, les valeurs correspondantes pour $\mathrm{S}$, celles pour $x$ étant déterminées à partir de l'enveloppe, en fonction de petits accroissements de $y$.

Dans la troisième étape, l'on admet, pour la plus faible valeur de $\mathrm{S}$, une section critique, de forme parabolique, et l'on calcule la largeur $b$, à partir de la relation:

$$
b=\frac{3 \mathrm{~S}}{2 y}
$$

La largeur $b_{1}$, correspondant à la profondeur suivante $y$, se détermine à partir de l'expression :

$$
\left(y_{1}-y\right) \cdot \frac{b_{1}+b}{2}=\mathrm{S}_{1}-\mathrm{S}
$$

et ainsi de suite, pour toutes les valeurs successives de $y$. Enfin, on relie tous les points ainsi déterminés par une courbe uniforme; laquelle représente le profil de la section critique.

\section{Emplois pratiques}

Outre ses intéressantes caractéristiques hydrauliques, la section critique pourrait sans doute se révéler d'un emploi utile dans les domaines de l'irrigation et du drainage. En donnant, par exemple, le profil de la section critique à la contraction d'un Venturi, ou d'un canal, à profondeur critique, de jaugeage des débits, on obtiendrait que les modifications du plan d'eau, soient minimales. Des études expérimentales complémentaires seront cependant nécessaires avant qu'il ne soit possible de dire avec quelle précision les hauteurs des plans d'eau, à l'amont d'une section critique, pourraient être déterminées.

Par ailleurs, il serait possible d'éviter les abaissements du plan d'eau, à l'amont d'une chute, ainsi que les phénomènes d'érosion du fond provoqués par ceux-ci, en donnant à la section de la chute, la forme de la section critique. C'est d'ailleurs cotte dernière possibilité qui fut à l'origine de notre étude de la section critique.

\section{RÉFÉRENCES}

(1) G. Formica. - Expériences préliminaires sur les pertes de charge dans les canaux, dues à des changement de section. A.I.R.H., Comptes rendus de la Sixième Assemblée Générale, La Haye, 1955. D-12.
(2) F.F. Escoffrer. - Détermination graphique de la ligne d'eau et calcul des remous. La Houille Blanche, $\mathrm{n}^{\circ} 3$, mai-juin 1951 , p. 411. 